\title{
Respiratory problems since birth to 12 years: What is causing morbidity and mortality in Sri Lanka?
}

\author{
K A W Karunasekera ${ }^{1}$, A F Fernando ${ }^{2}$, S M V Subasinghe ${ }^{3}$, B C Lakmini ${ }^{3}$
}

Sri Lanka Journal of Child Health, 2014; 43(1): 33-37

\begin{abstract}
Background: Respiratory tract disorders cause significant mortality and morbidity in children worldwide.

Objectives: To study the pattern of respiratory diseases and its seasonal variation amongst children admitted to hospital and assess causes of mortality due to respiratory diseases especially in children less than 5 years of age.

Method: A descriptive study was conducted at the University Paediatric Unit, Colombo North Teaching Hospital during 2010 and 2011. All children below 12 years admitted with respiratory tract disease (ICD10 classification) were recruited into the study. Data collection forms were filled by medical officers using patient records.
\end{abstract}

Results: Out of 13,356 admissions, 2,651 (19.8\%) were admitted with respiratory disease. Highest number of admissions (30.5\%) was in the 1 month to 2 year age group and $4.4 \%$ of admissions were neonates. Common causes of admission included unspecified lower respiratory tract infections (LRTI) (44.1\%), upper respiratory tract infections (URTI) (25.2\%), bronchial asthma (11.5\%) and bronchiolitis (7.0\%). Incidence of bacterial pneumonia was $0.95 \%$. Admissions due to respiratory diseases peaked in June (2010-20\%, 2011-16\%). Admissions with bronchial asthma were higher during the first half of year $(2010-86.3 \%, 2011-80.5 \%)$. The total number of deaths was 24 and $87.5 \%$ of these deaths were in children under 5 years. Out of under 5 year deaths 17 $(94.5 \%)$ were early neonatal deaths. The common causes of mortality under 5 years were surfactant deficient lung disease (43\%), meconium aspiration syndrome $(24 \%)$ and severe respiratory failure due to hypoxic ischaemic encephalopathy (19\%).

${ }^{1}$ Professor in Paediatrics, ${ }^{2}$ Associate Professor in Paediatrics, ${ }^{3}$ Temporary Demonstrators, Department of Paediatrics, Faculty of Medicine, University of Kelaniya

(Received on 20 June 2013: Accepted after revision on 26 July 2013)
Conclusions: LRTI, URTI, bronchial asthma and bronchiolitis were the main contributory factors to the morbidity. Mortality due to respiratory causes was $0.9 \%$ and was confined mainly to the neonatal period. Common causes of under-5 year deaths were surfactant deficient lung disease, meconium aspiration syndrome and respiratory failure due to hypoxic ischaemic encephalopathy.

(Key words: Respiratory problems; children; morbidity and mortality; Sri Lanka)

\section{Introduction}

Respiratory diseases are a leading cause of hospitalization in Sri Lanka and are the second commonest cause at all ages. $(10.4 \% \text { in } 2007)^{1}$. Diseases of the respiratory system are among the five leading causes of death in children less than 5 years in Sri Lanka ${ }^{1}$.

Among major causes of deaths in the under 5 year age group worldwide, $37 \%$ were neonatal deaths and $17 \%$ were post-neonatal acute respiratory tract infections ${ }^{2}$. Sri Lanka has a target of reducing less than 5 year mortality rate to 7.4 per 1000 live births by 2015 to achieve Millennium Development Goal 4 (MDG 4). Therefore knowledge on the pattern of respiratory diseases in children and their seasonal variation would help to identify the common diseases contributing to morbidity and mortality especially in children less than 5 years of age. Identification of diseases which cause mortality will also help to decide on allocation and distribution of health resources.

Besides morbidity and mortality, respiratory diseases have a major impact on the psychological aspects of the patient and the family. Furthermore, respiratory diseases are an economic burden on the family accounting for $7.2 \%$ of total personal medical spending in Sri Lanka in $2005^{3}$. This research was carried out to study the pattern of respiratory diseases and their seasonal variation in children needing inpatient care. The study also evaluated the causes of mortality due to childhood respiratory diseases, especially in children less than 5 years of age. 


\section{Method}

A prospective study was conducted at University Paediatric Unit, Colombo North Teaching Hospital for a period of 2 years starting from January 2010 . All children from birth to 12 years admitted with respiratory disease were recruited into the study. The diseases were classified according to the World Health Organization, International Classification of Diseases- version 10 (ICD - 10) ${ }^{4}$. All diagnoses were made by consultant paediatricians. Presence of high fever, cough, high C-reactive protein level and radiological evidence were the criteria used for the diagnosis of bacterial pneumonia. Clinical and radiological criteria were used to diagnose other respiratory diseases. Blood culture was not used as a tool to diagnose bacterial pneumonia because the yield in the paediatric age group was very $l_{0} w^{5,6}$. Data collection forms were filled by medical officers using patient records. Major causes for mortality were determined by the consultant paediatrician who cared for the baby.

\section{Results}

Total admissions during the 2 year study period were $13,356(6,851$ in $2010 ; 6,505$ in 2011). Of the total admissions 2,651 (19.8\%) (1,370 in 2010; 1,281 in 2011) were admitted with respiratory diseases. Fifty four percent $(53 \%$ in $2010 ; 55 \%$ in 2011$)$ were males. The age groups of children were birth to 28 days $(4.4 \%), 29$ days to 2 years $(41 \%), 2$ to 5 years $(30.5 \%)$ and 5 to 12 years $(24.1 \%)$.

Morbidity: Out of all admissions, the most frequent diseases were lower respiratory tract infections (LRTI) $(44.1 \%)$, upper respiratory tract infections (URTI) (25.2\%), bronchial asthma $(11.5 \%)$ and bronchiolitis $(7.0 \%)$. Overall incidence of bacterial pneumonia was $0.5 \%$ in $2010(\mathrm{~N}=7)$ and $1.4 \%$ in $2011(\mathrm{~N}=18)$ in all age groups. The distributions of diseases amongst different age groups are shown in Tables $1 \mathrm{a} \& 1 \mathrm{~b}$.

Seasonal variation: Admissions due to respiratory diseases peaked in June as shown in figure 1 . Seasonal variation in bronchial asthma was noted with a peak in first three months of the year with the least number in August (Figure 2).

Table 1a: Diseases among neonates

\begin{tabular}{|c|c|c|}
\hline Disease & $\mathbf{N}$ & $\%$ \\
\hline Acute upper respiratory tract infections & 17 & $14.6 \%$ \\
\hline Acute unspecified lower respiratory tract infections & 17 & $14.6 \%$ \\
\hline Respiratory distress of newborn (unspecified) (e.g. Transient tachypnoea of newborn) & 14 & $12.1 \%$ \\
\hline Respiratory distress syndrome of newborn & 14 & $12.1 \%$ \\
\hline Bronchiolitis (acute) & 14 & $12.1 \%$ \\
\hline Pneumonia (aspiration, ventilator associated \& bacterial) & 9 & $7.8 \%$ \\
\hline Respiratory failure & 5 & $4.3 \%$ \\
\hline Neonatal aspiration of meconium & 5 & $4.3 \%$ \\
\hline Birth asphyxia & 5 & $4.3 \%$ \\
\hline Congenital pneumonia & 4 & $3.5 \%$ \\
\hline Others (e.g. Milk aspiration, pneumothorax, polyps in the vocal cord and larynx) & 12 & $10.3 \%$ \\
\hline Total & 116 & $100 \%$ \\
\hline
\end{tabular}

Table 1b: Diseases among children 1 month up to 12 years

\begin{tabular}{|l|c|c|c|}
\hline \multicolumn{1}{|c|}{ Disease } & Up to 2 years & $\begin{array}{c}\text { Pre-school age } \\
(2-5 \text { years })\end{array}$ & School age \\
\hline Acute unspecified lower respiratory tract infections & $523(48.2 \%)$ & $385(47.6 \%)$ & $243(37.9 \%)$ \\
\hline Acute upper respiratory tract infections & $272(25.1 \%)$ & $222(27.4 \%)$ & $157(24.4 \%)$ \\
\hline Bronchiolitis (acute) & $149(13.8 \%)$ & $21(2.6 \%)$ & - \\
\hline Bronchial asthma & $60(5.5 \%)$ & $105(13 \%)$ & $138(21.5 \%)$ \\
\hline Tonsils (Hypertrophy) & $22(2 \%)$ & $25(3.1 \%)$ & $39(6.1 \%)$ \\
\hline Pneumonia (bacterial) & $6(0.6 \%)$ & $8(1 \%)$ & $6(0.9 \%)$ \\
\hline $\begin{array}{l}\text { Other (e.g. pharyngitis, tonsillitis, sinusitis, obstructive } \\
\text { laryngitis) }\end{array}$ & $52(4.8 \%)$ & $43(5.3 \%)$ & $59(9.2 \%)$ \\
\hline \multicolumn{1}{|c|}{ Total } & $1084(100 \%)$ & $809(100 \%)$ & $642(100 \%)$ \\
\hline
\end{tabular}




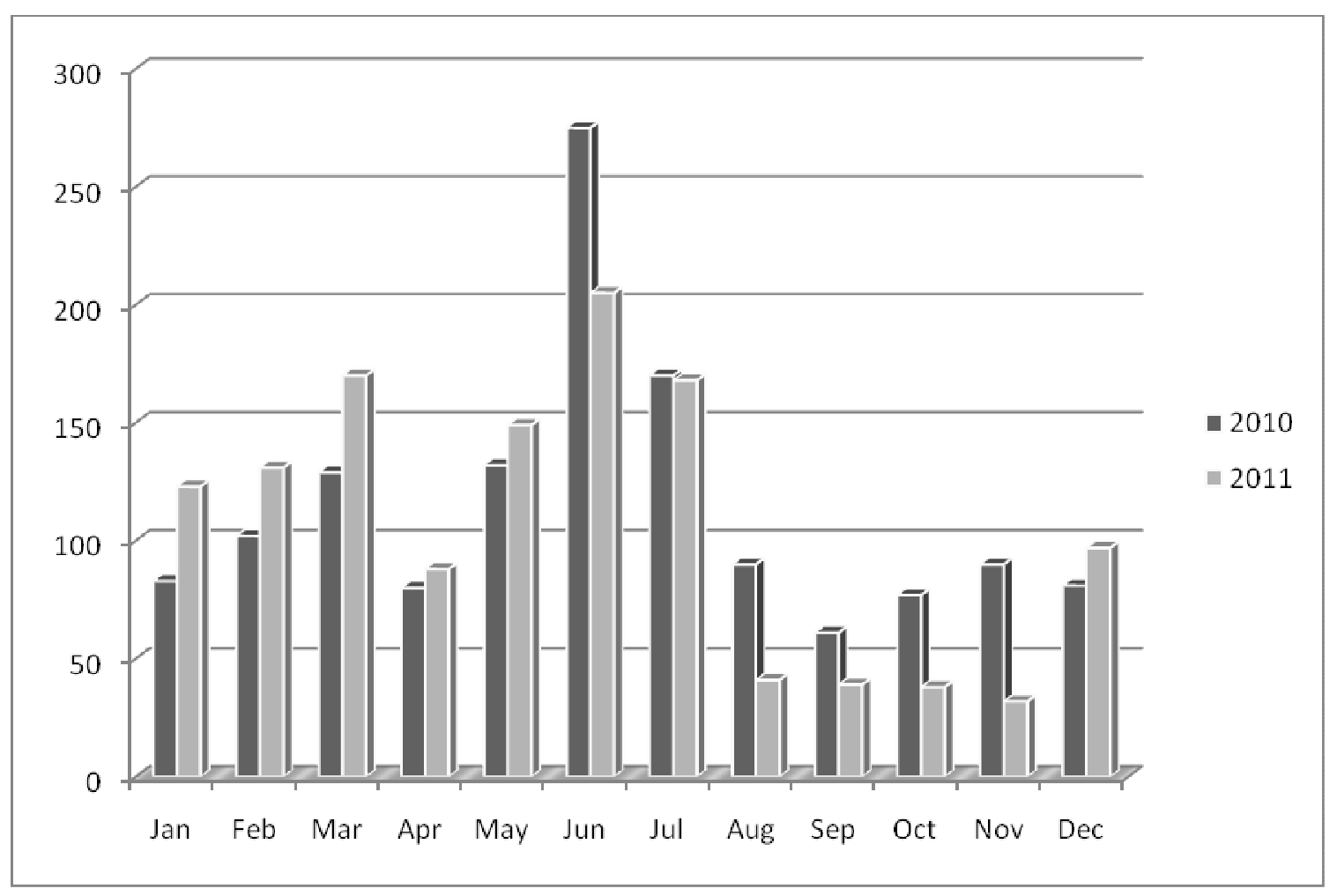

Figure 1: Admissions due to respiratory diseases

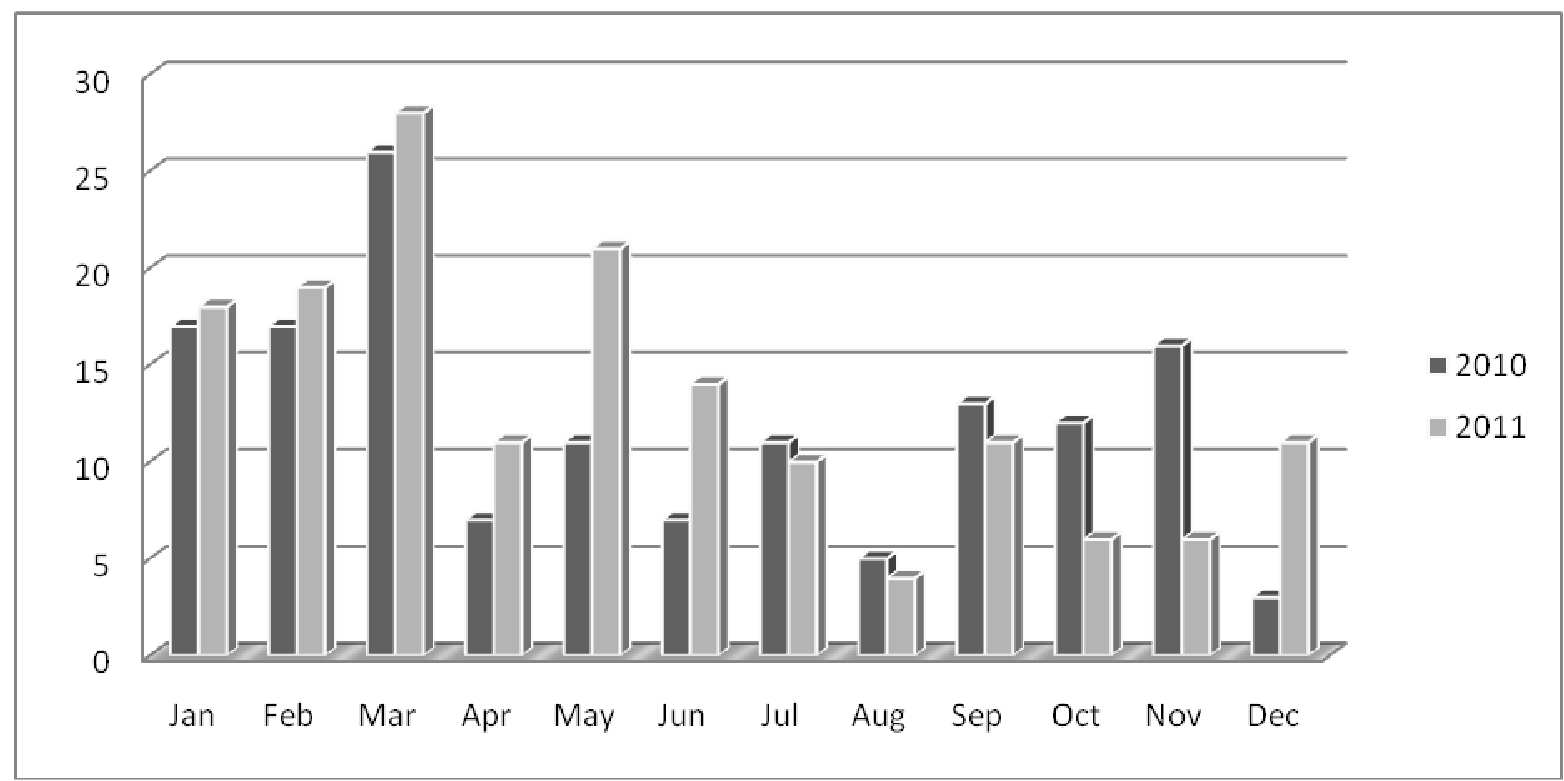

Figure 2: Seasonal variation of bronchial asthma

Nearly $9 \%$ of total admissions needed prior stabilization at the Emergency Department. These include nebulization and supplementation of oxygen.
Median duration of hospital stay was 3 days (range 1 - 60 days). The majority ( $82.5 \%$ ) were discharged home without requiring clinic follow up. 
Mortality: Twenty four $(0.9 \%)$ children died due to respiratory illnesses. Twenty one $(87.5 \%)$ of these deaths were among neonates and $78 \%$ were early

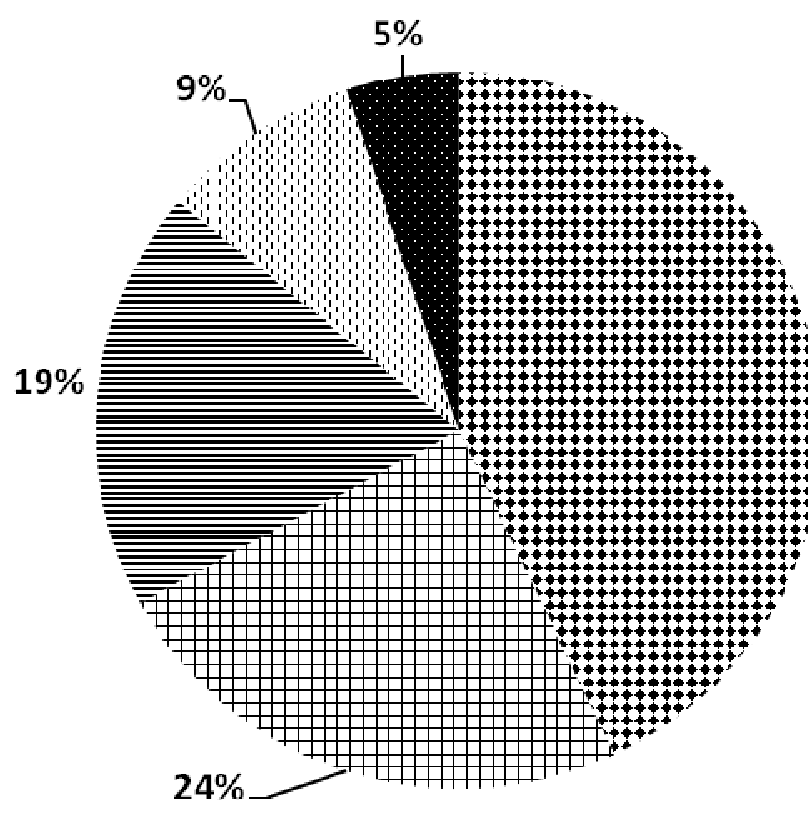

neonatal deaths. Under 5year mortality is shown in figure 3 .

\author{
I: Surfactant Deficient Luis \\ Disease \\ 4 Meconium Aspiration \\ Syndrome \\ 三Severe Hypoxic Ischemic \\ Encephalopathy \\ Aspiration Pneumonia
}

\title{
Heart Failure + LRTI
}

Figure 3: Under 5 year mortality

Three children who succumbed beyond the neonatal period up to 5 years had underlying co-morbidities such as aspiration pneumonia in a child with cerebral palsy, respiratory failure in a child with severe hypoxic ischaemic encephalopathy who had been ventilated for a long period, LRTI in a child with multiple congenital heart defects and severe heart failure.

Three deaths occurred in children more than 5 years of age and were due to aspiration pneumonia in a child with cerebral palsy, bacterial pneumonia in a child with Down syndrome, and bronchiectasis with Ig A deficiency.

\section{Discussion}

Admissions due to respiratory diseases in children accounted for nearly $20 \%$ of all indoor morbidity. The common respiratory causes in children seeking indoor medical treatment were URTI, LRTI, bronchial asthma and bronchiolitis which is in keeping with other studies ${ }^{7,8}$.
This study highlighted the occurrence of a seasonal variation in hospital admissions amongst respiratory diseases and bronchial asthma in keeping with other reported studies ${ }^{7,9,10,11}$. There is a change in the morbidity pattern in different age groups. Amongst neonates URTI and LRTI have outnumbered the respiratory distress syndrome and meconium aspiration syndrome, which may have been related to improved perinatal care.

More than $75 \%$ of the mortality occurred in the neonatal age group, although the total admissions in the above age group were less than $5 \%$ and the common morbidity was due to URTI and LRTI. The major contributors for mortality were due to surfactant deficient lung disease, meconium aspiration syndrome and severe hypoxic ischaemic encephalopathy. This may indicate that antenatal care and perinatal care given to these babies may not have been the best and hence there is a need for improvement, if we are to achieve MDG4. The morbidity and mortality due to bacterial pneumonia is 
noted to be low, which may be related to vaccination against Haemophilus influenza type $b$ and other childhood diseases such as measles and improvement in nutrition in childhood.

\section{Conclusions}

- $\quad$ LRTI, URTI, bronchial asthma and bronchiolitis were the main contributory factors to the morbidity.

- Mortality due to respiratory causes was $0.9 \%$ and was confined mainly to the neonatal period.

- Common causes of under-5 year deaths were surfactant deficient lung disease, meconium aspiration syndrome and respiratory failure due to hypoxic ischaemic encephalopathy.

This study indicates that neonatal diseases are the major contributors for the mortality. Therefore the health care providers should target the antenatal mother and the neonate to optimize care in reducing diseases such as meconium aspiration, hypoxic ischaemic encephalopathy and premature deliveries. This may have a great impact in reducing less than 5 year mortality and achieving MDG 4.

\section{References}

1. Annual Health Bulletin Ministry of Health 2007:109-121.

2. WHO. The Global Burden of Disease: 2004 update (2008).

3. Institute of health policy. Population ageing and health expenditure: Sri Lanka 2001-2101. March 27, 2007.

4. WHO. International Classification of Diseases: version 10

5. Han YY, Lee YL, Guo YL. Indoor environmental risk factors and seasonal variation of childhood asthma. Pediatric Allergy \& Immunology 2009; 20 (8):748-56. http://dx.doi.org/10.1111/j.13993038.2009.0087 1.x
6. Lynch T, Bialy L, Kellner JD, Osmond MH, Klassen TP, Durec T, et al. A systematic review on the diagnosis of paediatric bacterial pneumonia: when gold is bronze. PLOS One 2010; 5(8):e11989.

http://dx.doi.org/10.1371/journal.pone.0011989

7. Bezerra PG, Britto MC, Correia JB, Duarte Mdo $\mathrm{C}$, Fonceca AM, Rose K, et al. Viral and atypical bacterial detection in acute respiratory infection in children under five years. PLOS One 2011; 6(4): 18928.

http://dx.doi.org/10.1371/journal.pone.0018928

8. Laurent C, Dugue AE, Brouard J, Nimal D, Dina $\mathrm{J}$, Parienti, JJ, et al. Viral epidemiology and severity of respiratory infections in infants in 2009: A prospective study. Pediatric Infectious Disease Journal 2012; 31: 827-31. http://dx.doi.org/10.1097/INF.0b013e318256600 5

9. Feikin DR, Njenga MK, Bigogo G, Aura B, Aol G, Audi A, et al. Etiology and incidence of viral and bacterial acute respiratory illness among older children and adults in rural Western Kenya, 2007-2010. PLOS One 2012; 7(8):e43656. http://dx.doi.org/10.1371/journal.pone.0043656

10. Tao Y, An X, Sun Z, Hou Q, Wang Y. Association between dust weather and number of admissions for patients with respiratory diseases in spring in Lanzhou. Science of the Total Environment 2012; 423:8-11.

http://dx.doi.org/10.1016/j.scitotenv.2012.01.064

11. Han YY, Lee YL, Guo YL. Indoor environmental risk factors and seasonal variation of childhood asthma. Pediatric Allergy \& Immunology 2009; 20 (8):748-56. http://dx.doi.org/10.1111/j.13993038.2009.0087 1.x 